\title{
Teachers as Critical Mediators of Knowledge
}

\section{MARK MASON}

This paper considers the question of the role of teachers with respect to knowledge, an issue that has been reopened as a consequence of the widespread interest in outcomes-based education. Proponents of an outcomes-based education are sometimes guilty of defending a role for teachers that is limited to facilitation. Against this rather passive understanding of the role of teachers, the paper defends a notion of teachers as critical mediators of knowledge. The role of teachers as mediators of knowledge is developed from debates in epistemology about knowledge and truth. The role of teachers as socio-cultural critics, analogous to the role of art critics, is developed from debates around knowledge, values, and the politics of curriculum design. These two roles are synthesised into teachers as critical mediators of knowledge.

\section{WHAT IS AN APPROPRIATE ROLE FOR TEACHERS WITH RESPECT TO KNOWLEDGE?}

The fascination with outcomes-based education, that has had education planners from Scotland to Hong Kong via New Zealand and from the USA to South Africa in its thrall, has rekindled the somewhat hoary debate in philosophy of education concerning the most appropriate role of teachers with respect to knowledge. In an outcomes-based education (OBE), teachers are understood primarily as facilitators of learning, rather than as transmitters of a given body of knowledge. There is, of course, nothing new in this conception of teachers as facilitators. But in claiming a space for OBE, its defenders have stressed the importance of procedural knowledge as opposed to what they perceive as a rather heavy emphasis on propositional knowledge, using the distinction drawn by Ryle (1971).

Teachers concerned with the transmission of a body of knowledge, claim the defenders of OBE, might be overly committed to merely drilling by rote what Ryle refers to as propositional knowledge: "lists of truths or facts, for example the proposition that $7 \times 7=49$, etc., the proposition that Waterloo was fought in 1815, etc., and the proposition that Madrid is the capital of Spain, etc.” (1971, p. 453). While Ryle accepts this as an indispensable part of teaching, he draws our attention to procedural knowledge, which is held as an essential aspect of an outcomes-based education: "Teaching-to so and so, and Learning-to so and so, that is, ... the development of abilities and competences ..., the acquisition of skills, knacks and efficiencies" (ibid., p. 454). "[L]essons in drawing, arithmetic and cricket - and, if 
you like, in philosophy”, Ryle points out, "cannot consist of and cannot even contain much of dictated propositions" (ibid.). While initiation into these skills may amount to little more than drilling, defenders of OBE have stressed the role of teachers as facilitators of the development of competences at a level higher than drilled propositions or low-level skills. "Effective possession of a piece of knowledge-that involves knowing how to use that knowledge, when required, for the solution of other theoretical or practical problems", maintains Ryle (ibid., p. 225). The distinction he draws is between knowledge as a "museum-possession" and as a "workshoppossession" (ibid.), citing an example of a student who may understand the premises and the conclusion of an argument, and the meaning of these terms, but fail to grasp how the conclusion follows from the premises (ibid., p. 216). Knowing how to reason, in other words, is not reducible to knowledge of particular propositions. Ryle shows, moreover, in a simple proof that need not concern us here (see p. 224), that the concept of knowledge-how is logically prior to the concept of knowledge-that (ibid., p. 215).

Many interpreters of OBE thus defend a role for teachers as facilitators of the development of skills in their learners, as they focus on the outcomes of learning and the application of knowledge by their learners. Their stress is on facilitation as against an overly strong emphasis on the transmission of knowledge, which they perceive to be characteristic of teaching that is dominated by a concern with propositional knowledge. They might sometimes, however, be missing the fact that low-level skills are often drilled in a transmission model of teaching, and setting up transmission models of teaching as something of a straw man. For example, in his defence of "progressive" against "traditional” education, Dewey (1963) surely concluded the case against teaching conceived solely as the transmission of knowledge with his argument from pragmatism about the importance of the educational experience.

Dewey criticised traditional forms of education for their emphasis on transmitting static bodies of information to students who were required to be docile and obedient. He saw the dominant interaction of traditional education as one of imposition, which limited participation by students in their learning to merely the acquisition of information (ibid., pp. 17-19). In progressive forms of education, he saw the encouragement of student expression and individuality, and free activity in place of external discipline (ibid., pp. 19-20). His concern, in seeking to avoid a simple rejection by progressive educators of the tenets of traditional education and the thoughtless pursuit of its opposite, was to defend what he saw as "an intimate and necessary relation between the processes of actual experience and education” (ibid., p. 20). In the following section I consider briefly Dewey's defence, from a pragmatist understanding of knowledge, of the educational experience in learning.

In some cases, such as in South Africa, where rote learning has been the order of the day as a consequence of Apartheid education policies (the difficulties of teaching and learning in a second or third language, the large number of underqualified teachers, the scarcity of desks, textbooks and stationery, the pervasively authoritarian culture of education, the overcrowded nature of classrooms, and very high pupil:teacher ratios), defenders of OBE are justified in their concerns about the ubiquity of transmission styles of teaching. OBE is being adopted there in an attempt to counter the widespread rote learning that is so often associated with transmission models of teaching. Thus in South Africa particularly, education planners and teachers tend to be all too easily seduced by the notion of teachers as facilitators of skills development towards learning outcomes. The understanding of teachers as 
facilitators, however, casts teachers in an exceedingly passive role, which is selfevidently problematic. Thus has the debate about the most appropriate role for teachers with respect to knowledge been reopened.

I have argued elsewhere (Mason, 1999) that teachers should be concerned to seek continually a careful balance among propositional, procedural, and dispositional knowledge. An education oriented too strongly around propositional knowledge tends too easily to treat knowledge as fixed or given. Among others, the pragmatists and the postmoderns have warned us against an overly strong commitment to this route. Furthermore, as Ryle pointed out, learning endless facts is pointless unless students can use their new knowledge to change the way they approach new situations and problems. On the other hand, an education oriented solely around procedural knowledge and learning outcomes tends to treat learners as little more than functionaries who rather mindlessly execute the tasks required of them. A critical orientation is significantly dependent on a thorough knowledge and understanding of the material, and not just on the skills associated with it. And an education concerned only with dispositional knowledge is quickly susceptible to the charge of indoctrination. In truth, propositional, procedural, and dispositional knowledge are inextricably linked to each other: to talk of one without the others is absurd. Propositional knowledge must in these terms still constitute an important aspect of an outcomes-based education. If traditional forms of education over-emphasised propositional knowledge, then new curricula should of course stress the importance of procedural and dispositional knowledge, but certainly not at the expense of content and theory.

What then are the implications of this debate among the three kinds of knowledge for the debate around the role of teachers with respect to knowledge? If education under the rubric of propositional knowledge lends itself too quickly to transmission styles of teaching, with which are all too easily associated the presentation of knowledge as fixed or given, the treatment of learners as passive or as empty vessels, and a tendency towards rote learning; if an outcomes-based education oriented around procedural knowledge has been interpreted too quickly as implying facilitative styles of teaching, with which is associated a teacher who is too passive; and if an overly strong emphasis on dispositional knowledge opens teachers too easily to the charge of indoctrination; what is an appropriate role for teachers with respect to these three kinds of knowledge?

My intention here is to defend a role for teachers as critical mediators of knowledge, which describes their role both as mediators of knowledge, and as sociocultural critics. First, drawing on debates around knowledge and truth, and briefly on Dewey, Vygotsky, and Freire, I will develop a defence of teachers as mediators of knowledge. And second, drawing on debates around knowledge, values, and the politics of curriculum design, with brief reference to Gramsci and others, I will develop a defence of teachers as socio-cultural critics. A combination of these roles, intended to cover widely the issues generated by debates around both knowledge and truth, and knowledge and values, yields a role for teachers in terms of what I have described as critical mediators of knowledge (Mason, Adendorf, et al., in press). I do not intend to rehearse here the well-established positions in these debates, but rather to draw on some of their salient features in my defence of teachers as critical mediators of knowledge. 


\section{KNOWLEDGE AND TRUTH: TEACHERS AS MEDIATORS OF KNOWLEDGE}

Dewey's defence of the role of experience in education is based in his pragmatist understanding of knowledge. For him, knowledge is an instrument for action, rather than a passive reflection of given or fixed essential phenomena. Teaching is thus not about the transmission of a static body of representational knowledge, but about creating worthwhile educational experiences. It is the teacher's task to create a learning environment which "will interact with the existing capacities and needs of those taught to create a worthwhile experience" (1963, p. 45). This interaction of a learner's existing capacities with the appropriately structured challenges of the learning environment enables the learner to develop new knowledge. For Dewey, a worthwhile educational experience is one that stimulates the desire to go on learning. The teacher thus plays a vital role in carefully structuring an educational environment with which the learner, given his current knowledge and potential, can interact. In her careful, thoughtful, and active creation of a worthwhile educational experience - one which will in turn lead to further experience and ultimately to growth - the teacher is certainly not a merely passive facilitator, even less a transmitter of static information. This role is best described in terms of the mediation of knowledge, where the teacher is actively involved in getting her hands dirty with the messiness and unfinished business of pragmatic knowledge. Dewey's truth is empirically, and not revelationally, derived, and the teacher mediates that derivation.

Vygotsky's approach to teaching for cognitive development is also far more than mere facilitation. Like Dewey, Vygotsky (1978) stresses the importance of the experience of the learner in learning. For Vygotsky, the teacher's role is to lead the learner to higher levels of thinking by interpreting and giving significance to things and events. This process he called intentional mediation. As in the term's etymology, the teacher stands in the middle, between the learner and the knowledge to be learned. His is not a pragmatist view of knowledge, but no matter for us here: my concern is more with the mediational role of teachers, and less with the nature of knowledge. For Vygotsky, mediation involves leading learners to increasing levels of complexity by providing scaffolding for them to reach the next level. Such scaffolding involves and is associated with assistance through explanation and instruction, interpretation, modelling, the indication of significance and relative importance, careful questioning to lead learners towards the development of the concept, giving feedback, and the like. Of course, more scaffolding is provided initially, and the support progressively removed until the learner becomes independent.

The teacher as mediator is always aware of the learner's level of understanding and development so that learning can be appropriately targeted. As Dewey talks about the current knowledge, level of experience, and capacity of the learner, so Vygotsky talks about the learner's Current Level of Development. And while Dewey talks about endless growth through educative experiences, Vygotsky describes the level of complexity for which the learner strives as the Potential Level of Development. Teaching for effective learning should be directed at what Vygotsky calls the Zone of Proximal Development, that zone lying between the learner's current and potential levels of development. Such teaching involves intentional mediation, and not facilitation or transmission.

Freire's (1970) images of learners as empty vessels into which the teacher poured knowledge, and of education akin to banking, where the teacher makes deposits of knowledge to withdraw them in a later examination, against which he 
contrasted his notion of a problem-posing education, are by now well worn. For him, education suffered from "narrative sickness" (ibid., p. 57), and the teacher's monologue was to be replaced in problem-posing education by a dialogue between teacher and learner. From his existential premises, learners are conscious and intentional beings, and liberating education consists "in acts of cognition, not transfers of information" (ibid.). For our purposes, it is worth noting that he calls not for silence on the part of the teacher (by now we know well that Freire and silences do not sit happily together) to replace her previous monologue, as might be inferred from a strong version of teaching as facilitation, but for a dialogue. And the questions asked by the teacher, in a Socratic sense if you will, are mediational.

I hope to have clarified two things from this quick reference to Dewey, Vygotsky, and Freire: on the one hand, an epistemological and a moral objection to teachers as transmitters of knowledge - to reify all knowledge into objective permanence is to miss what the pragmatists taught us at the beginning of this century, and what the postmoderns are reminding us about the nature of truth now; and to treat learners as passive receptacles is to undermine their integrity and potential as human beings. More than this, while transmission models might make for effective rote learning, they don't make for the effective internalisation of concepts, and nor do they lend themselves to critical thought. And on the other hand, that none of Dewey, Vygotsky, or Freire talks about teaching as merely the facilitation of learning, as merely the setting up of free play environments for more or less haphazard shots at goal. Each talks about teachers as actively mediating between what is known and what is not yet known by the learner. Teachers are most appropriately in these terms, mediators of knowledge.

\section{KNOWLEDGE AND VALUES: TEACHERS AS SOCIO-CULTURAL CRITICS}

Teachers as mediators of knowledge is then the first half of the defence I wish to offer of teachers as critical mediators of knowledge. That first half of the argument depended on debates in epistemology about knowledge and truth, and on insights from educational theory to do with effective learning. That teachers should be critical mediators depends on arguments from the domain of values and the politics of curriculum design. This is equally well trodden territory: from Gramsci's unusual notion of a conservative education for radical politics, so well described by Entwhistle (1979), through Postman and Weingartner's (1969) Teaching as a Subversive Activity (and Postman's (1979) subsequent Teaching as a Conserving Activity), to Young's (1971) Knowledge and Control, Apple's (1977) Ideology and Curriculum, and Giroux's numerous publications on the subject (his Teachers as Intellectuals: Toward a Critical Pedagogy of Learning (1988) is a good example), the arguments between those who defend teaching as a conserving practice, and those who defend teaching as a radically critical practice, have been well rehearsed. I want to offer here a new and different notion of the teacher as critic, drawing on the analogy of a film or art critic.

The first and most obvious criterion of knowledge selection for inclusion in the curriculum is its truth status. That debate, from realist or objectivist through revelational to pragmatist, to social constructivist and to Nietzschean and postmodern perspectives, informed our discussion concerning the mediational role of teachers with respect to knowledge. More intractable than these truth criteria are the divisions of power in the political domain that influence the selection of material for inclusion 
in and exclusion from the curriculum. The question of whose knowledge is taught lies at the centre of the debates alluded to in the previous paragraph. Interestingly, Gramsci's arguments do not provide support for the positions defended by the likes of Young and Apple. At the core of their positions was the contention that the curriculum represents merely the knowledge, worldview, and values of powerful groups in society, and not necessarily the 'best' or 'most valuable' knowledge available. Gramsci, on the other hand, argued that the curriculum represented the most rigorous and worthwhile knowledge to date, and that the children of the poor should be steeped in this officially sanctioned (for good reason) knowledge for the very purpose of taking on the wealthier and more powerful groups with the best means available. For him, it was definitely a case of 'Latin for the peasants' rather than 'people's mathematics'.

Gramsci the Marxist notwithstanding, the popular consensus among progressive educators concluded from this debate that spanned the sixties and seventies was that the role of teachers with respect to knowledge was to be radically critical, to expose the officially sanctioned knowledge of the curriculum as merely reflecting the interests and worldview of society's ruling groups. (That is, until the postmoderns came along and taught us that all knowledge is only locally true, and that there isn't much point, at least in strong postmodern perspectives, in political struggle anyway.) In revisiting this debate as we begin to doff our caps in a post-postmodern direction, I want to defend again the role of teachers with respect to knowledge as socio-cultural critics, but in a different sense of the term. The progressive consensus has offered a rather stark use of the term critic: teachers in this role were to offer a critical perspective on their society so that their learners could be empowered by their questioning and rejection of the status quo ${ }^{1}$. This in contrast to the conservative perspective which understood teachers as responsible for the reproduction of sociocultural arrangements and practices by transmitting them to their learners.

It is obviously not the role of teachers simply to reproduce the status quo by transmitting the knowledge and worldview of their culture in an unquestioning manner. It is also not their role zealously to undermine everything in their society by criticising every aspect of their culture. To borrow from Postman's titles, I want to suggest that teaching is both a conserving and a subversive activity, and that this notion is captured in the use of the term critic, analogous to the theatre or art critic. The task of the art critic does not lie in the trivial sense of the term, to criticise the weaknesses of the work. It is to make the work more accessible to the viewer, in all its nuances and subtleties, in what it says and in its silences, in its history and context and in what it presages, in its complexities of meaning and import, in the questions it raises and their consequences. In like manner, teachers as socio-cultural critics are responsible for making the culture, worldview, social arrangements, and everyday practices of their society more accessible to their students. This would mean raising a lot of what they assume as normal or natural to the level of conscious critical analysis and assessment - by asking questions about how they view the world, about those arrangements and practices that they take for granted. It would mean helping their learners to see that their assumptions are not always natural, but very often socially constructed. It would also mean that they open up the richness of their culture to their students, in order that they might understand and perhaps come to value at least some of the norms of the society in which they are socialised.

Teachers as socio-cultural critics means, then, that teachers are both conservers of culture involved in its reproduction through critical transmission to the young, and critics of culture aiming to make their socio-cultural practices more 
accessible to their students so that they might make their own choices about them. It means, for example, that a teacher teaching in a strongly liberal culture, who is therefore responsible for steeping her students in the values of individual rights, personal autonomy, and freedom of choice in the definition and pursuit of the good life, might also encourage her students to question what may be lacking in such a worldview. Mindful of Robert Bellah's Habits of the Heart: Individualism and Commitment in American Life (1985), and of Charles Taylor's Ethics of Authenticity (1991), she might encourage her students to consider how self-fulfilment in a strongly liberal culture is often understood in primarily personal terms, thus too easily relegating both intimate relationships and those in the broader social realm to a merely instrumental significance. Her students might develop a more critical perspective on their strongly individualist worldview: they might realise the sad consequences for the quality of intimate relationships that are entered into for instrumental reasons; they might realise the consequences of an instrumental orientation to broader social relationships - the negation of responsibility to community, and hence of the potential for succour in community, and the marginalisation of political citizenship and participation (leading ultimately and ironically to lower levels of personal freedom).

Teaching in the role of a socio-cultural critic means, for example, that a teacher teaching in a strongly communitarian culture, let us say a Confucian culture, who is therefore responsible for steeping her students in the values of filial piety and harmonious relationships, might also encourage her students to consider some of the difficulties potentially consequent on an excessive concern with respect for authority. She might help her students to develop confidence in their own abilities to ask probing questions and to adopt a sceptical perspective. They might come to accept that asking questions of parents, teachers, political leaders, of any figure in authority, is not necessarily and immediately disrespectful. They might thus develop their own skills of critical thinking, and discover that it is not antithetical to mutually respectful relationships. Teachers as socio-cultural critics means, to repeat by way of conclusion to this aspect of the argument, that teachers are both conservers of culture at least partly responsible for its reproduction through critical transmission to the young, and also critics of culture aiming to make their socio-cultural practices more accessible to their students so that they might make their own choices about them.

\section{CONCLUSION: TEACHERS AS CRITICAL MEDIATORS OF KNOWLEDGE}

My concern here has been with the role of teachers with respect to knowledge, a debate that has been reopened as a consequence of the current interest in outcomesbased education. Out of the context of debates about the nature of knowledge and truth, I have described the role of teachers as most appropriately, mediators of knowledge. These debates commonly revolve around the question whether knowledge is fixed as universally true or whether it is provisional and tentative. Since these two poles are continually in tension with one another, and since most other debates in the field take place somewhere within this tension, I have suggested that mediating knowledge is a more appropriate role for teachers, rather than - on the one hand - simply transmitting knowledge as reified, and rather than - on the other adopting a merely passive facilitative role. 
And emerging from debates about knowledge, values, and the politics of curriculum design, I have described the role of teachers as most appropriately, sociocultural critics. These debates commonly take place between the opposite poles of teachers as conservers of culture and teachers as cultural subversives. Trying to tread a more sensitive and careful path through this debate, I have suggested that teachers are more appropriately socio-cultural critics, where the term critic is analogous to the art critic whose task is to make the work more accessible to the viewer. Teachers are both conservers of culture and cultural subversives.

A synthesis of these two roles as mediators of knowledge and as socio-cultural critics is what leads us to what I have described as an appropriate role for teachers with respect to knowledge: that of critical mediators. Teachers as critical mediators are mindful of the inadequacies of the bald transmission of knowledge and of the merely passive facilitation of learning, seeking a balance in their teaching between these two extremes. And they are equally aware of the tensions between the opposite poles of teaching for reproduction and teaching for subversion, seeking a sensitive and careful path. This is not teaching on the comfortable middle road of each of these two continua. It is teaching in the full awareness of the difficulties and tensions involved, in the knowledge that we will never find a perfect balance, but with the courage always to try.

Correspondence: Mark Mason, Department of Education, The University of Hong Kong, Pokfulam, Hong Kong.

\section{NOTES}

1. Elizabeth Ellsworth (1989), among others, seriously questioned the efficacy of this notion of critical teaching in her article, Why doesn't this feel empowering? Working through the repressive myths of critical pedagogy.

\section{REFERENCES}

Apple, Michael (1979) Ideology and Curriculum (London, Routledge and Kegan Paul).

Bellah, Robert (1985) Habits of the Heart: Individualism and Commitment in American Life (Berkeley, University of California Press).

Dewey, John (1963) Experience and Education (New York, Collier Books, Macmillan Publishing Company).

Ellsworth, Elizabeth (1989) Why doesn't this feel empowering? Working through the repressive myths of critical pedagogy, Harvard Educational Review, 59.3, pp. 297-324.

Entwhistle, Harold (1979) Antonio Gramsci: Conservative Education for Radical Politics (London, Routledge and Kegan Paul).

Freire, Paulo (1970) Pedagogy of the Oppressed (New York, Continuum).

Giroux, Henry (1988) Teachers as Intellectuals: Toward a Critical Pedagogy of Learning (Granby, Mass., Bergin \& Garvey).

Mason, Mark (1999) Outcomes-based Education in South African Curricular Reform, Cambridge Journal of Education, 29.1, pp. 137-143.

Mason, Mark, Mike Adendorf et al. (In press) Being a Teacher (Cape Town, Oxford University Press).

Postman, Neil (1979) Teaching as a Conserving Activity (New York, Delacorte Press). 
Postman, Neil and Charles Weingartner (1969) Teaching as a Subversive Activity (New York, Delacorte Press).

Ryle, Gilbert (1971) Knowing how and knowing that, in Collected Papers, Volume 2: Collected Essays 1929-1968 (London, Hutchinson).

Ryle, Gilbert (1971) Teaching and training, in Collected Papers, Volume 2: Collected Essays 1929-1968 (London, Hutchinson).

Taylor, Charles (1991) The Ethics of Authenticity (Cambridge, Mass., Harvard University Press).

Vygotsky, Lev (1978) Mind in Society: The Development of Higher Psychological Processes, ed. Michael Cole et al. (Cambridge, Mass., Harvard University Press).

Young, Michael (ed.) (1971) Knowledge and Control: New Directions for the Sociology of Education (London: Collier-Macmillan). 